•综述・

\title{
栽培植物野生近缘种的保护与利用
}

\author{
赵 耀 ${ }^{1}$ 李耕耘 $^{2}$ 杨 继 ${ }^{2 *}$ \\ 1 (南昌大学生命科学研究院流域生态学研究所, 南昌 330031) \\ 2 (复旦大学生物多样性科学研究所, 上海 200438)
}

\begin{abstract}
摘要: 栽培植物是人类赖以生存和发展的重要物质基础。全球人口与人均需求量的持续增长导致对植物资源的需 求与日俱增。栽培植物较低的遗传多样性是限制其产量增长和质量提高的主要因素。栽培植物野生近缘种在自然 环境中积累了丰富的遗传变异, 并在应对环境变化的过程中产生了很多新的适应性状, 是栽培植物种质创新和品 种改良的重要遗传资源。然而, 栽培植物野生近缘种的存续和自然进化因生境破坏以及全球气候变化等正面临严 重威胁, 需要采取有效的措施进行保护。本文总结了国内外对栽培植物野生近缘种进行原生境保护与迁地保护所 取得的进展, 并基于我国实际情况提出了栽培植物野生近缘种的保护建议。此外, 本文还对栽培植物野生近缘种 利用技术进行了梳理, 探讨了栽培植物野生近缘种遗传资源可持续利用的新思路。最后, 我们以长江流域几种代 表性栽培植物为例, 对主要作物类型的保护与利用情况进行了讨论。
\end{abstract}

关键词：栽培植物; 野生近缘种; 原生境保护; 迁地保护; 利用

\section{Conservation and utilization of wild relatives of cultivated plants}

\author{
Yao Zhao ${ }^{1}$, Gengyun Li $^{2}$, Ji Yang ${ }^{2 *}$ \\ 1 Center for Watershed Ecology, Institute of Life Science, Nanchang University, Nanchang 330031 \\ 2 Institute of Biodiversity Science, Fudan University, Shanghai 200438
}

\begin{abstract}
Cultivated plants are the most important material basis for human survival and development. Growing global human population and personal demands result in increasing consumption of plant resources. The low genetic diversity of cultivated plants is a key factor that restricts production and quality improvements. Wild relatives of cultivated plants have accumulated rich genetic variations and adaptive traits during the process of long-term adaptive evolution, thus can be used as genetic donors in germplasm innovation and improvement of cultivated plants. However, the persistence and evolution of wild relative populations are threatened by habitat destruction and anthropogenic climate change. This review summarizes the progress of in situ and ex situ conservation of wild relatives of cultivated plants and offers conservation suggestions for wild relatives of cultivated plants based on the current situation in China. Moreover, technologies for the utilization of wild relatives of cultivated plants are reviewed and new insights on the sustainable use of genetic resources of wild crop relatives are also discussed. Finally, the status of conservation and utilization of the main cultivated plants that originated from the Yangtze River Basin are investigated, with four plants of different uses used as representatives.
\end{abstract}

Key words: cultivated plants; wild relatives; in situ conservation; ex situ conservation; utilization

栽培植物是人类对野生植物进行长期栽培、驯 化、选择和改良的产物(卢宝荣, 2014), 其主要类型 包括粮食作物、经济作物、蔬菜作物、果树作物、 花卉、饲用作物和药用植物等(董玉琛和刘旭,
2008)。栽培植物与人类文明的发展息息相关。自从 约一万年前以人类对野生动植物的驯化为标识的 农耕文明诞生以来, 农耕生产提高了环境的承载上 限, 促进了人口的增长与文明的进步; 随文明发展

收稿日期: 2018-01-30; 接受日期: 2018-04-16

基金项目: 上海市科学技术委员会课题(14DZ2260400)和国家自然科学青年基金(31600293)

* 通讯作者 Author for correspondence. E-mail: jiyang@fudan.edu.cn 
而不断提高的科技水平又促进了农耕生产, 形成正 反馈。然而，这种发展模式终将受到资源的制约而 难以持续, 尤其在近 100 年, 由于全球人口数量加 速增长, 急剧增大的资源需求与有限的土地、水及 其他自然资源之间出现了难以调和的矛盾。

在栽培植物驯化过程中, 人类针对目标性状 (如株型、落粒性与果实大小等)不断进行定向选择, 形成瓶颈效应(bottleneck), 使得每一代都只有个别 或少部分植株的后代被保留下来。持续的定向选择 作用导致在与驯化性状相关的等位基因位点上具 有选择优势的等位基因频率升高，总体等位基因的 多样性下降; 由于基因搭载效应(hitch-hiking)的存 在, 相邻位点的遗传变异水平也会受到相似影响 (选择性清除, selective sweep) (Ingvarsson, 2002; Palaisa et al, 2004; Nielson, 2005; Zhang et al, 2017)。 尽管栽培植物在引种过程中可能产生新的遗传变 异以适应变化的环境或满足不同的驯化目的, 发生 “二次起源”, 总体上栽培植物的遗传多样性水平依 然远远低于其野生祖先(Doebley et al, 2006; Purugganan \& Fuller, 2009; Meyer et al, 2012)。驯化造 成的遗传多样性水平下降和环境适应性降低, 不但 极大地限制了栽培植物的利用潜力, 而且给农业生 产带来潜在的风险, 最著名的案例当属 19 世纪 40 年 代爱尔兰由马铃薯晚疫病(potato late blight, 病原菌 为致病疫霉Phytophthora infestans)引起的饥荒。栽 培植物较低的遗传多样性已成为限制农业发展的 因素之一。

栽培植物野生近缘种是指与栽培植物具有较 近亲缘关系、并能与其发生基因交流的野生祖先 种、同属近缘种以及由栽培植物野化产生的杂草等 (Maxted et al, 2006; 于燕波等，2013; 卢宝荣， 2014)。在数百万年的自然进化过程中, 栽培植物野 生近缘种积累了丰富的表型与遗传变异, 能抵御各 类生物(如: 病虫害、杂草)或非生物(如: 低温、高 盐、干旱)胁迫的影响(Castañeda-Álvarez et al, 2016); 这些优良性状和有益基因可作为遗传供体用于对 栽培植物进行改良, 提高单位面积产量, 增强抗病 性或抗逆性(卢宝荣, 2014; Zhang et al, 2017)。瓦维 洛夫(1982)曾预测野生近缘种会在农业发展中起重 要作用, 事实也的确如此: 自 1945年以来, 全球 $30 \%$ 的作物增产得益于野生近缘种在作物育种中的 使用(Pimentel et al, 1997), 每年产生的收益约1,150
亿美元(Maxted et al, 2010)。野生近缘种是栽培植物 种质创新和品种改良的天然基因库，是保障全球粮 食安全、促进农业可持续发展的战略资源(杨庆文等, 2013; 于燕波等, 2013)。

中国是世界八大作物起源中心之一，栽培植物 种质资源极其丰富。长江流域是世界水稻(亚洲栽培 稻Oryza sativa) 种植的发源地, 且果树与水生作物 的物种数量居世界第一(瓦维洛夫, 1982)。丰富的植 物资源不仅孕育了长江流域以稻作文化为特色的 中国古代文明，而且支撑了长江经济带的繁荣和发 展。然而, 由人口增长和城市化进程导致的生境破 坏、资源过度利用、环境污染、盲目引种以及全球 气候变化等对该地区栽培植物野生近缘种的存续 和进化造成了严重威胁, 致使大量自然群体消失, 栽培植物野生近缘种遗传多样性丧失; 加之对植物 资源的需求不断增加, 对栽培植物野生近缘种的保 护与利用日益紧迫。由于缺乏长期跟踪调查与评估, 制定合理的植物资源保护和可持续利用方案面临 挑战。本文在分析国内外栽培植物野生近缘种研究 和保护现状的基础上，探讨了对栽培植物野生近缘 种资源进行保护和可持续利用的新思路和新方法, 并对长江流域代表性栽培植物的保护与利用情况 进行了讨论。

\section{栽堷植物野生近缘种的保护}

\section{1 原生境保护与迁地保护}

为了加强生物多样性保护, 减小当前物种灭绝 速率，促进人类社会的可持续发展，保护生物学试 图通过揭示物种灭绝与濒危机制、分析生物群落和 生态系统遭受破坏的机理和恢复基础等, 为制定保 护计划和策略提供依据(Soulé, 1985; Frankham et al, 2002)。针对栽培植物野生近缘种, 目前在原生境保 护和迁地保护方面都开展了一系列工作。

原生境保护是在自然条件下对栽培植物野生 近缘种群体及其进化过程进行保护 (Meilleur \& Hodgkin, 2004; Dulloo et al, 2010)。原生境保护可以 在一个地点对多种遗传资源进行保护, 不需要设置 多种储存条件来满足不同种质的保护需要，而且免 去了迁地保护中繁杂的人工更新工作(Jarvis et al, 2000)。原生境保护能够使物种保存更多的遗传多样 性，以具备更大的进化潜力(Hendry，2013)。因此, 世界各国都十分重视濒危植物与资源植物的原生 
境保护, 建立了许多重要野生资源植物原生境保护 点, 例如以色列的野生小麦(Triticum spp.)保护点、 墨西哥的野生玉米(Zea spp.)资源保护点以及埃塞 俄比亚的野生咖啡(Coffea spp.)保护点等(Song et al, 2005; 于燕波等, 2013)。2001-2014年间, 我国已建 了189个物理隔离保护方式和 72 个主流化保护方式 的农业野生植物原生境保护点(中国生物多样性国 情研究报告编写组, 2016)。与此同时, 还通过自然 保护区建设间接对多个物种实行原生境保护, 共建 立自然保护区 2,750 处，占中国陆地面积的 $14.88 \%$ (http://sts.mep.gov.cn/zrbhq/), 此外还建立了国家级 森林公园881处、各类保护小区5万余个(http://zgslgy. forestry.gov.cn/), 初步形成了野生植物原生境保护 网络。

迁地保护是将植物种子或活体植株移到人工 创造的适宜环境中保存, 避免受自然灾害或人为因 素的影响。迁地保护对于原生境遭到严重破坏、种 群存续受到巨大威胁的物种具有重要意义, 是进行 抢救性保护的有效手段(Gómez-Campo，1985; Dulloo et al, 2010)。开展迁地保护需要先了解被保护材 料的遗传背景, 因此其收集和储藏的种质遗传多样 性是可控的, 有利于后续的研究和利用(Jarvis et al, 2000)。例如, 英国邱园(Kew Gardens)的千年种子库 项目 (Millennium Seed-bank Project)就是为保护英 国和全球植物种质资源而于 2000 年建立的(van Slageren, 2003), 其目的除了储藏英国所有 1,400多 种野生植物种子外, 还要保护世界野生植物中的 $10 \%$ 免于灭绝。由挪威政府、全球作物多样性信托 基金会和北欧遗传资源中心共同运作管理的、位于 挪威斯瓦尔巴特群岛的全球种子库被誉为延续人 类希望的“末日容顶”，其宗旨是把世界各地的植物 种子保存在永久冻土带的地下败藏库中, 以防因天 灾人祸造成全球物种锐减或灭绝, 并帮助人类恢复 和延续农业生产(Fowler, 2008)。我国政府也十分重 视栽培植物及其野生近缘种种质资源的保护, 陆续 建立了多个国家作物种子库和种质圃(附录1) 以及 中国西南野生生物种质资源库等(董玉琛，1999; 李 德铢等, 2010)。据联合国粮食及农业组织的报告 (FAO, 2014), 全球目前约有 1,750 座种质库, 保存了 约750万份各类农作物的种质资源(李德铢等, 2010)。

\section{2 栽培植物野生近缘种资源的保护建议}

物种的存续和发展在很大程度上取决于其对
环境变化的适应能力和进化速率。野生种相比驯化 后的物种具备更强的适应性、更快的进化速率 (Prentis et al, 2008; Carroll et al, 2014; Ramesh et al; 2017)。迁地保护在栽培植物野生种质资源的收集和 保藏过程中发挥了重要作用, 但与原生境保护相比, 迁地保存只是一种权宜之计。除了在实际操作过程 中难以全面评价其所蕴含的遗传多样性、需要定期 更新和繁殖、成本较高等问题外，迁地保护最突出 的问题在于把植物个体或群体与其原本所生存的 自然生境隔离开来，制约了其进化潜力的发挥 (Jarvis et al，2000), 也无法了解和跟踪全球变化背 景下它们的进化动态, 使得挖掘和利用新的具有丰 富变异的基因资源无从谈起。野生近缘种保护的关 键是维持其进化潜力, 保护其与环境变化关联的进 化过程。迁地保护本质上是一种“静态”保护，对自 然生境丧失且极度濒危的物种而言意义重大。相比 之下，原生境保护让植物种群始终暴露在自然选择 和适度的人类干扰作用下，使其保持进化潜力，相 对投入也远远小于迁地保护。

在我国过去几十年的原生境保护实践中，尚存 在一些问题，如人工干预的栖息地恢复工程并未完 全满足重点保护物种的生理及行为等生物学特性 的适应性要求, 未能充分保障被保护的野生种群的 进化潜力。迁地保护则主要针对栽培作物的地方品 种，对于野生资源收集不足。因此，在保护策略上 仍存在一些需要关注和改进的方面:

(1)植物遗传资源保护工作关注最多的是栽培 作物的祖先种, 对其他具有潜在利用价值的近缘种 关注程度不够。我国基于几十年来对植物物种资源 本底调查的结果编写了《中国物种红色名录》(汪松 和谢炎, 2004)与《中国植物红皮书》(傅立国, 1991), 制定了《国家重点保护野生植物名录》(http://sts.mep. gov.cn/swwzzybh/)。在有限的资源条件下不可能对 所有物种都给予充分的保护, 需要优先对重要作物 的野生近缘种进行分级评定(于燕波等, 2013)。由于 人类对资源的需求状况处在动态变化过程中, 一些 目前虽尚未得到充分开发、但对粮食安全和生态系 统健康具有潜在价值的物种需要予以重视, 例如: 菰(Zizania latifolia)、栎属植物(Quercus spp.)、文冠 果(Xanthoceras sorbifolium)等。

(2)在遴选保护对象并建立原生境保护点时, 应重视不同地区以及不同部门间的交流和协调，自 
然保护区规划应尽可能覆盖重要物种丰富度较高 的地区，同时避免针对一些热度较高的“明星”植物 开展重复性的保护工作。

(3)确定保护对象之后, 对其遗传多样性特点、 分布范围、致危因素和机制等进行深入的分析和了 解, 运用分子标记分析或基因组测序对野生近缘种 自然种群的遗传结构、基因流距离和亲缘关系等进 行估计。了解被保护对象的遗传多样性特点、交配 系统以及种群动态等, 不但是对其进行有效保护的 前提, 也是开展种质资源动态保护的基础性工作 (黎否和陈家宽, 2014; 黎裕等, 2015)。此外, 基于标 本数据库信息和环境因子数据, 通过生态位模拟分 析栽培植物野生近缘种遗传变异与分布区的关系, 推测影响种群遗传结构和遗传多样性组成的关键 环境因子, 对确定优先保护区域和优先保护居群, 制定科学的保护策略具有重要意义, 也已经有了成 熟的案例(Castañeda-Álvarez et al, 2016; Hanson et al, 2017)。

(4)加强对保护区(点)内被保护对象生长和进化 动态的监测与管理, 减少受保护遗传资源类型的不 确定性; 在关注被保护对象存续状态的同时, 还要 关注与其伴生的其他生物的种群动态(Jarvis et al, 2000)。栽培植物野生近缘种保护的最优理念是对生 态系统的动态保护, 保持其结构和功能的稳定性, 保证生态系统中各个功能类群的良好运行, 增强生 态系统自身的适应能力和与环境的连通性 (Barnosky et al, 2017)。

(5)重视全球气候变化对野生植物分布和种群 变化的影响。通过长期、系统的追踪监测, 建立有 效的数据库, 发展野生植物对全球气候变化响应的 量化指标及相应模型, 确定全球气候变化的植物多 样性敏感区与对气候变化敏感的植物类群, 从而为 保护提供前瞻性建议(黎磊和陈家宽, 2014)。

(6)全面评价迁地保护保存材料的遗传多样性, 并严格按照保育规程定期进行更新和繁殖; 若条件 允许, 每隔一段时间从野生种群中采集材料用以动 态补充现有种质资源的基因库。

\section{栽培植物野生近缘种遗传资源的可持续利月}

栽培植物的遗传改良和种质创新是满足日益 增长的人类需求、保障粮食安全、实现农业可持续 发展的基础。通过挖掘栽培植物野生近缘种的优异
基因并加以利用，不仅能提高作物产量，改善作物 品质，而且能拓展栽培植物基因库遗传多样性，降 低遗传脆弱性。

栽培植物野生近缘种遗传资源可持续利用的 基本思路是: 利用栽培植物野生祖先、同属近缘种 以及栽培种野化形成的杂草能快速适应环境变化 的特性，在采取合理的保护措施为这些野生近缘类 群遗传多样性和适应性进化过程的维持提供必要 支持的前提下，通过不断转化新的遗传技术，从中 挖掘符合人类需求的自然变异, 为栽培植物品种改 良和人类应对生存压力持续提供有利的遗传多样 性资源。

\section{1 传统利用方式与成果}

杂交育种是传统上栽培植物遗传改良的基本 途径(Warschefsky et al, 2014; 秦丹丹等, 2016)。对 于一些生长周期较长以及繁殖方式复杂的植物, 杂 交育种很难在短期获得成果，在自然生境中寻找发 生自然杂交的植株后代能缩短育种进程(黄宏文, 2009)。迄今为止，大部分栽培植物的品种改良都是 以野生近缘种丰富的遗传变异为基础。例如，人类 发展史上第一次 “绿色革命”就源于小麦和水稻中矮 秆基因的发现和应用(贾继增等，2015); 向小麦中 引入其祖先种一粒小麦(T. monococcum)的耐盐基因, 培育出了高产耐盐小麦(Munns et al, 2012); 从野生 香蕉(Musa acuminata)中发掘了可用于栽培香蕉 $(M$. nana)品种改良的抗枯萎病基因(陈雅平等，2007); 亚洲栽培稻(O. sativa)和非洲栽培稻(O. glaberrima) 从稻属其他十几个近缘种中获取了大量与抗逆、抗 病和增产相关的基因(Jena, 2010)。

栽培植物野生近缘种利用的另一种方式是直 接针对特定的性状开展人工驯化。自农耕文明诞生 起, 人类尝试驯化新的栽培植物的努力从未停止 (Willcox, 2005; Fuller, 2007; Barton et al, 2009)。越 只有少数粮食作物得到了驯化，随着人类认识自然 和改造自然能力的提升, 驯化作物的数量迅速增 加。迄今大部分有价值且易于驯化的植物已被人类 改造为栽培植物, 农作物的数量趋于稳定; 以果树 为例, 20 世纪仅有猕猴桃(Actinidia chinensis)、蓝莓 (Vaccinium spp.)、䱮 (Butyrospermum parkii)与澳洲 核桃(Macadamia ternifolia)等少数驯化成功的案例 (Diamond, 2002)。当前对新物种的驯化已形成较为 
成熟的策略: 首先对有驯化潜力的野生物种进行详 尽的评价, 了解其适生区域、需求的生态因子、生 活史、遗传资源分布以及可驯化性状的变异模式; 然后从遗传品系和农艺性状上着手进行育种试验; 最后选择合适的商业模式推广新的驯化作物 (Dehaan et al, 2016)。目前人们更多注重于提升农作 物的品质与特性, 使得栽培植物品种呈现多样化, 以满足愈加多元化的市场需求。

\section{2 现代遗传技术}

近20年来, 科学家与育种工作者在培育现代作 物品种时使用了不少新的遗传技术, 包括分子标记 辅助育种 (marker assisted selection) 与遗传工程 (genetic engineering)等, 已在主要作物中开发出了 很多具有优良性状的新品种(Hajjar \& Hodgkin, 2007)。基于基因组研究进展而诞生的新技术，如基 因组选择(genomic selection)与基因组编辑(genomic editing)等, 也逐渐从实验室里的模式材料研究转化 到作物改良的实际应用当中(Ronald, 2014; Jacob et al, 2017)。

\subsection{1 分子标记辅助育种}

以往作物育种主要依据表型性状进行篮选, 很 少考虑性状形成的分子机理和遗传背景, 对控制目 标性状的基因数目以及各个基因的贡献大小也不 清楚(刘忠松, 2014)。此外, 表型性状是基因型与环 境互作的结果, 直接对性状进行选择不仅易受环境 效应的干扰, 而且不一定能够准确选择和利用控制 优良性状的基因型。尽管目前对不同栽培植物野生 近缘种遗传资源类型及驯化性状的遗传背景已有 初步认识(Doebley et al, 2006; Gross \& Olsen, 2010), 但野生物种的遗传多样性实际上处在动态变化中, 而且一些具有潜在适应意义和利用价值、只在特定 环境下才表达的 “隐藏”(cryptic)遗传变异也很难被 发现。

分子标记辅助育种通过准确鉴别不同杂交后 代的基因型并与表型进行关联分析，找到与控制目 标性状的基因紧密连锁的分子标记, 依据这些标记 对后代进行选择，以实现对性状进行定向选择的目 的(Collard et al, 2005)。与单纯的表型性状选择相比, 分子标记辅助选择受环境及发育时期等因素影响 较小, 无组织特异性, 具有较高的稳定性和可重复 性, 并能通过基因型检测在育种早期去除大多数分 离后代, 减少分离群体种植规模, 可以提高选择准
确性和育种效率(Moose \& Mumm, 2008)。例如, 科 研工作者成功通过分子标记在一个具有耐水淹性 状的印度地方水稻品种(FR13A)中定位到与该耐性 紧密相关的基因组区域Sub1, 并以分子标记辅助技 术为基础育成一系列商业品种，有效地提高了南亚 与东南亚地区的水稻产量(Xu et al, 2006)。

\subsection{2 基因组选择}

目前已完成基因组测序的植物中 $60 \%$ 以上是栽 培植物(Michael \& Vanburen, 2015)。随着大部分栽 培植物基因组测序的完成, 对它们的野生祖先和近 缘种的测序工作也已逐渐展开, 并进行了一系列相 关研究, 包括: (1)直接与栽培植物基因组进行比对, 鉴定驯化位点(Subbaiyan et al, 2012; Brozynska et al, 2015); (2)为多倍体栽培植物的基因组测序提供参 考, 降低复杂的多倍体作物基因组的拼装难度 (Brozynska et al, 2015); (3)基于全基因组水平的基 因型鉴定形成对遗传资源的“预览”, 提升新基因挖 掘的精准性和效率, 为栽培植物改良和种质创新奠 定基础。

基因组选择是一种基因定位、亲本选配和后代 选择的新模式，其实质是基于全基因组水平的分子 标记与表型性状的关联赋值分析, 具有较好的应用 前景。基因组选择利用参照群体(reference population)的表型数据和覆盖整个基因组的分子标记(如 SNP标记), 通过关联分析估计出每一个标记对选择 性状的效应值(marker effect), 然后将选育后代个体 携带的各标记的效应累加起来，直接估计出它们的 基因组育种值(genomic breeding value), 对没有表 型记录但有基因型信息的预测群体(inference population)个体进行表型预测, 并选择优良单株(Heffner et al, 2009)。与传统的分子标记辅助选择相比, 基因 组选择不是依赖于一组特殊的分子标记, 而是对覆 盖整个基因组的所有标记进行整体分析，将每个起 作用基因的效应包括在内，因此尤其适合由多基因 控制的复杂性状或数量性状的选择分析。不仅如此, 基因组选择通过关联分析能直接定位控制目标性 状的关键基因，增加了选择的精准性，并可以同时 对多个性状进行选择，显著提高了选择的效率。基 因组选择技术已经广泛运用于玉米、小麦和高粱 (Sorghum bicolor)等重要粮食作物的新品种培育 (Hamblin et al, 2005; Chao, 2007; Heffner et al, 2009)。 


\subsection{3 基因工程与基因组编辑}

栽培植物野生近缘种基因库中固然存在许多 具有潜在利用价值的基因, 但也有一些不利于驯化 的基因(例如与落粒性、种子休眠性以及有毒次生代 谢产物等野生特征相关的基因), 如果仅通过传统 的杂交育种来剔除这些基因是非常困难的(Diamond, 2002)。随着人类对生物体认识的不断深入以 及生物技术的发展, 通过基因工程的方法将目的基 因导入受体植株或将有害基因从植物中剔除, 无疑 是最为直接的手段。转基因技术已经十分成熟, 尽 管其安全性仍存在争议, 但部分产品已经开始商业 化生产且取得了较好的效益(卢宝荣, 2014)。

新近出现的以CRISPR/Cas9为代表的基因编辑 技术能对植物基因组进行高效、精准、特异的修饰， 实现对内源基因的定向改造、缺失或者基因的插入 与替换, 为优质基因资源的高效利用和实现目标性 状的精准改良提供了新的途径, 甚至可能颠覆传统 的杂交育种方式(周想春和邢永忠, 2016; Karkute et al, 2017)。近来, 美国冷泉港实验室通过CRISPR/ Cas9介导的基因编辑, 成功地对一个控制番茄果实 大小的QTL主效基因的启动子序列进行精确诱变, 创造出新的遗传变异, 导致后代群体出现果实大小 表型的连续变异, 再从中篮选出符合需求的材料进 行育种, 这为解析控制数量性状的复杂基因调控网 络提供了有效手段(Rodriguez-Leal et al, 2017)。

通过整合基因组编辑与基因组选择等技术，可 以挖掘鉴定优异基因，设计最佳的符合育种目标的 基因型以及实现目标基因型的亲本选配和后代选 择策略，提高栽培植物育种的预见性和育种效率， 实现从传统的“经验育种”到定向、高效的“精确育 种”的转化。对于通过这些最新技术获得的产品的 安全性评估也应同步开展。

\section{3 进化农业生态理论及其应用}

传统育种方式是通过在个体层面的篎选找出 个体表型最优的基因型，再以其为亲本培育并构建 高产的子代种群。然而, 用进化理论重新审视这种 沿用了上千年的育种理念，会发现其可能并非是提 高作物产量的最优解。种群是进化的最基本单元, 一些进化生物学家和生态学家认为育种应当以提 高种群总适合度(产量)为目标, 而非强调提高个体 的适合度(Donald, 1981; Zhang et al, 1999; Denison et al, 2003; Weiner, 2003)。他们基于这个理念提出了 进化农业生态(evolutionary agroecology)理论, 也称 “达尔文农业” (Darwinian agriculture)。

进化农业生态的核心思想是：在给定的环境下， 农作物个体表型优秀的一系列基因型之中适合度 最高的基因型并不一定会具备最高的群体产量，因 为个体适合度的提高会加剧个体间对资源的竞争， 从而表现出负面的群体效应。与之相对的是, 较弱 的个体适合度可能表现出在群体层面的“合作”，提 高总产量(Donald, 1981; Zhang et al, 1999; Weiner, 2003)。兰州大学李凤民研究团队与丹麦哥本哈根大 学Jacob Weiner教授合作，利用栽培小麦作为实验 材料, 初步验证了进化农业生态理论(Weiner et al, 2017)。如果此理论在更多的作物中得以验证，可能 对当前的作物育种理念形成很好的补充，并引导育 种专家从栽培作物的祖先种或野生近缘种中節选 出符合进化生态农业要求的种质资源。

\section{3 长江流域栽堷植物野生近缘种资源保护旦 案例}

长江流域是我国生物多样性的核心区域之一, 我国近一半的特有栽培植物起源于长江流域, 已建 立的植物原生境保护点 $30 \%$ 以上位于长江流域(中 国生物多样性国情研究报告编写组, 2016)。然而, 长江流域作物及其野生近缘种遗传资源的研究严 重不足，保护、开发和利用成效并不显著，存在大 量研究与保护的空缺。由于对野生植物资源的保护 力度和开发程度受野生植物所属资源类型、研究背 景、商业价值以及文化传统等多种因素的影响，应 分别评价不同类型作物的保护与利用现状，为制定 遗传资源的保护与可持续利用的相关对策提供参 考(Dehaan et al, 2016)。

粮食作物野生近缘种无疑是最重要的植物资 源，因此对其采取了最为严密的保护措施，相关的 开发与利用研究也最为深入。果树作物因为产品的 商业化程度较高、市场需求大，其野生资源的保护 与开发也得到了较多关注，但传统育种方式的周期 较长, 限制了新品种开发的速度。蔬菜作物的地域 特征与季节性比较强, 种类繁多且相互间可替代性 高，因此其野生近缘种受到的关注不多; 经济作物 野生近缘种的保护与利用存在明显不平衡现象, 具 有较高经济价值的作物获得了高度重视，而其他多 数经济作物仍局限于传统的利用方式，不仅栽培种 
的驯化程度不高, 对野生近缘种资源也少有针对性 的保育措施。在此我们针对长江流域几种主要作物 类型的代表种及其野生近缘种资源的保护与利用 情况进行案例分析。

\section{1 粮食作物一一普通野生稻}

我国共有3种野生稻, 分别是普通野生稻 $(O$. rufipogon)、药用野生稻(O. officinalis)和疮粒野生稻 (O. granulata), 其中普通野生稻是亚洲栽培稻的祖 先种, 是重要的战略资源(Song et al, 2005; 赵耀, 2014)。

考古资料证实, 距今 10,000 年前, 栽培稻在长 江中下游地区开始被驯化，普通野生稻是该区域习 见物种(Kovach et al, 2007)。游修龄(2009)考证普通 野生稻有历史文献记录的分布区最北可达黄河流 域。由于气候变化和人类影响, 如今只有两个高度 隔离的普通野生稻种群存在于长江流域, 大部分种 群分布于珠江流域。尽管栽培稻野生种群的自然分 布出现了衰退, 但长江流域依然是毫无争议的稻作 核心区。

20世纪80年代, 我国对野生稻资源进行了全国 范围内的普查, 对几乎所有普通野生稻的自然种群 做了鉴定与评价。随着人类活动对自然环境的扰动 不断加剧，我国普通野生稻资源受到极大破坏，自 然种群面积不断减小, 甚至有些分布点已经绝迹。 台湾的普通野生稻于1978年灭绝; 云南省曾有26个 普通野生稻分布点, 现已消失 24 个, 仅剩景洪和元 江两个点, 景洪的原生分布点也因2011年机场扩建 基本消失, 元江种群面积则极度萎缩; 福建漳浦的 原生点被漳汕高速公路所取代; 广东、广西和海南 三省也有 $80 \%$ 的分布点消失(赵耀, 2014)。

鉴于普通野生稻的重要价值, 相关部门采取了 许多措施对其进行保护。截至2009年, 我国共建立 了15个普通野生稻原生境保护点, 并在广西南宁与 广东广州分别建立了野生稻迁地保护种质圃, 同时 在中国农业科学研究院的主导下构建了普通野生 稻种质资源的种子库(杨庆文等, 2013)。对比原生境 保护和迁地保护种群的遗传变异发现, 原生境种群 遗传多样性要显著高于迁地保护种群, 这不仅说明 了建立原生境保护的重要性, 同时也暗示迁地保护 应当注意扩大种群的规模并定期进行种群复壮。运 用分子标记对江西东乡和湖南茶陵的原位保护效 果进行评价发现, 被围墙隔离保护起来的种群遗传
变异只占原来大种群的 $67.9 \%$, 提示原位保护应当 注重保护整个原生生境(Qian et al, 2005)。我们在实 地调查中还发现, 广东高州的两个原生境保护点核 心区围墙内野生稻的生长状态劣于围墙外自然生 境中的群体, 这提示水泥围墙一类的物理隔离方式 对保护可能是不利的, 适度的扰动更有利于植物物 种的保护, 生境的动态变化是原生境保护中最重要 且需要长期监控的问题(于燕波等，2013; 赵耀, 2014)。另外，在制订保护策略时应当先评估被保护 种群的有效种群大小。如果有效种群太小, 建立原 生境保护点也不能避免种群绝灭, 不如通过迁地保 护进行人工繁殖，广东增城普通野生稻原位保护点 就是一个典型的例子。总体上看，我国对普通野生 稻资源的保护投入非常大，也起到了一定的效果， 但是保护理念还相对落后，没有有效地把保护生物 学研究成果与实际保护措施结合起来(Song et al, 2005)。

我国在野生稻资源利用方面取得了相当多的 成果。早在 20 世纪30年代, 丁颖就首次尝试育成了 第一个具有普通野生稻遗传背景的水稻品种; 袁隆 平继而利用在野外发现的野生稻雄性不育系实现 了杂交稻育种的历史性突破(赵耀, 2014)。现代育种 业从野生稻获得了多个重要基因, 用以改良栽培稻, 培育出了多个具有抗虫、耐旱或耐盐碱的优秀水稻 品种(Vaughan, 1994), 包括我国最近取得突破性进 展的“海水稻”和“再生稻”。对野生稻近缘种的利用 同样取得了一定成绩，从药用野生稻和疮粒野生稻 中分别分离出了抗稻飞亲与抗白叶枯病的主效基 因, 有望运用到栽培稻育种中(王布哪等, 2001; 宁 茜等, 2014)。

在保护方面，鉴于粮食作物(如谷物、豆类等) 大多具有良好的研究背景和迫切的应用需求, 对其 祖先种以及野生近缘种的保护也有许多年积累下 来的资料可供参考, 因此可把粮食作物野生近缘种 作为保护生物学研究的模式系统, 整合不同的理论 和方法开展研究和实践, 发展有效的可供推广的保 护措施。此外，也应大力尝试利用最新的生物技术 对粮食作物野生近缘种的优质基因资源进行挖掘 和利用，以满足日益增长的人类需求 (Jacob et al, 2017)。

\section{2 果树作物一一猕猴桃}

猕猴桃(Actinidia spp.)为原产中国的野生藤本 
果树, 是 20 世纪人工驯化的四大栽培果树之一(狝 猴桃、蓝莓、鳄梨与澳洲核桃)。中国是狝猴桃的起 源和分布中心。狝猴桃主要分布在长江流域上游秦 岭以南、横断山脉以东的山林中(董玉琛和刘旭, 2008)。

猕猴桃的利用历史悠久, 在 4,000 多年前的石 家河文化遗迹中就曾发现狝猴桃种子遗存, 从唐代 开始出现少量的栽培。猕猴桃的商业化栽培与驯化 始于20世纪初, 1904年, Allison在新西兰播种从中国 湖北宜昌获得的美味猕猴桃(Actinidia deliciosa)种 子, 1910年得到果实，进而由Hayward在1930年培育 出著名的海沃德(Hayward)品种, 此后猕猴桃的商 业栽培在新西兰兴起, 直到20世纪70年代初, 开始 在世界范围迅速发展(董玉琛和刘旭, 2008)。除新 西 兰外, 智利、意大利、法国和日本都是猕猴桃生产 大国。反观中国, 直到 20 世纪 80 年代才开始小规模 的猕猴桃栽培生产, 90年代初, 中国猕猴桃生产进 入大发展时期, 栽培面积迅速扩大, 总产量跃居世 界第一，但单位面积产量仍较低(黄宏文, 2009)。

猕猴桃为雌雄异株植物, 在杂交育种时, 由于 无法通过雄株的表型来预测后代中雌性个体的果 实性状，只能通过加大杂交组合数量的方法尝试发 现新的品种, 因此育种难度较高。即便是最先开始 猕猴桃育种工作的新西兰, 多年来也并未通过杂交 育种培育出显著优于海沃德的美味猕猴桃新品种。 我国科研人员从 20 世纪 50 年代开始收集和研究野 生猕猴桃, 于1980年创建了中国科学院武汉植物园 猕猴桃资源圃。该圃收集保存猕猴桃属植物 61 个种 和变种, 110 个国内外狝猴桃品种(系)以及3万余株 种内和种间杂交个体, 是目前国内外狝猴桃属植物 遗传多样性覆盖面最广、种质资源最丰富的基因库 (黄宏文, 2009)。对猕猴桃野生近缘种资源的收集和 保护极大地促进了我国狝猴桃的育种工作, 虽然相 较国外起步较晚, 但发展潜力巨大。我国不但从陕 西周至县和湖南凤凰县的野生种群中选育出新的 美味猕猴桃品种 “秦美”和 “米良 1 号”, 还开创性地 对中华猕猴桃(A. chinensis)进行了驯化, 培育出黄 色果肉的商品猕猴桃。目前黄色果肉的中华猕猴桃 主要有两个品种，一种是由中科院武汉植物园在江 西省武宁县发现的中华猕猴桃野生优秀植株发展 而来的“金桃”，另一种是新西兰从我国引种的中华 猕猴桃的杂交后代培育出的“Hort16A”。不仅如此,
我国还从四川和湖北的野生中华猕猴桃中选育出 红心品种“红阳”等。除中华猕猴桃外，对软柊猕猴 桃(A. arguta)和葛束猕猴桃(A. polygama)的驯化也 取得了较大进展。

猕猴桃这一案例直接体现了栽培植物野生近 缘种在新作物开发以及育种中的重要性。新西兰百 年来的园艺成果和商业化运营终究受限于种质资 源，相比之下我国坐拥丰富的野生猕猴桃资源，在 猕猴桃产业的发展上有望后来居上。我国具有世界 最丰富的果树资源(瓦维洛夫, 1982), 除已驯化的果 树外，还有拐余(Hovenia dulcis)、刺梨(Rosa roxburghii)、沙棘(Hippophae spp.) 以及木通(Akebia quinata)等具有较大利用潜力的物种。对我国特有的 栽培果树, 如中国樱桃(Prunus pseudocerasus)、枇杷 (Eriobotrya japonica)等进行遗传改良也势在必行。此 外，黄宏文(2009)通过回顾猕猴桃驯化改良和产业 发展的百年历史，提出了利用自然杂交带的基因渐 渗作用开展野生植物新种质和新基因型发掘的新 思路，可有效促进我国部分特有木本作物的育种。

\section{3 蔬菜作物一一莲}

莲(Nelumbo nucifera)是我国栽培面积最大、种 质资源最为丰富的一种水生蔬菜。莲的根茎(藕)不 但可作蔬菜食用, 莲子和叶还可作药用, 其花也具 有重要的观赏价值。莲在我国的栽培历史悠久, 距 今7,000多年前的河姆渡文化遗迹中就曾发现莲的 孢粉, 在距今 5,000 多年前的仰韶文化遗址出土了 碳化莲子，3,000多年前已出现有关莲的文献记载 (董玉琛和刘旭, 2008)。考古发掘还证实，在2,000多 年前的西汉时期, 莲藕已作为蔬菜食用。莲子生产 可追溯至1,000年前的南唐梁代，但大面积种植则 始于清代。野生的莲为亚洲广布, 其近缘种美洲黄 莲 (N. lutea)为美洲广布种, 两个物种无明显生殖隔 离。我国具有丰富的野生莲资源, 全国除青海与西 藏外的大小湖泊中皆有分布，且变异类型众多。

在长期栽培和驯化过程中, 莲已分化出藕莲、 子莲、花莲3大类型。藕莲以采收肥大的根状茎为 目的，其根状茎大小、入泥深浅和产量等性状有明 显差异; 子莲以采收种子为目的, 其果实大小、形 状、结实率、心皮数和花数等性状存在分化; 花莲 则以观赏为主要目的, 其花色与花型是主要的选择 性状。分子生物学证据表明3种类型的驯化莲之间 存在明显的遗传分化(郭宏波等, 2004)。较为优秀的 
藕莲种质资源集中分布在长江中下游地区, 子莲种 质资源则局限于湖南、江西和福建等地。运用现代 育种手段选育出的品种的农艺性状显著高于野生 种和地方品种(董玉琛和刘旭, 2008)。

我国在 20 世纪 80 年代开始进行莲的种质资源 收集, 构建了莲的国家种质圃(武汉)。目前, 种质圃 收集了莲种质资源500多份, 其中绝大部分为栽培 品种, 包括藕莲、花莲各200多份, 子莲20多份, 野 生莲相对较少, 仅有20余份。由于我国自然湿地的 面积不断缩小，野生莲资源面临生境丧失的威胁; 不仅如此, 栽培莲的大面积扩张导致从栽培种到野 生种的基因渐渗概率大幅提升。我国至今尚未对野 生莲的种质资源进行详实的调查和种群遗传多样 性评估(Yang et al, 2013), 使原生境保护难以有效开 展, 制订迁地保护计划也缺乏可靠的证据。对莲栽 培品种的保护与利用还存在一些问题, 包括: 栽培 种的起源尚不清楚; 现有栽培品种品系不纯; 缺乏 莲种质资源的种子保存库等。

蔬菜作物不但物种数量较多, 而且由于人类选 择作用的多样化, 使得同一物种分化出许多栽培品 种(如夢卜、甘蓝); 蔬菜作物对应的野生近缘种的 数量也极其庞大, 难以实现大规模的保护与开发, 因此需要发展灵活且有针对性的保护与利用策略。

一方面要重视对市场普及面广、种植规模大的重要 蔬菜作物的遗传资源收集与评价, 尤其对于非原产 的作物，应通过多种途径积极获取更多遗传资源， 建立种质库; 另一方面加强对我国特有野生近缘种 的保护与利用。在实施长江大保护的战略背景下, 应积极协调地方政府以及区域科研力量对具有地 域特色的作物(例如水生蔬菜)的遗传资源进行广泛 收集和研究, 关注水生蔬菜作物在长江流域农耕文 明起源中的重要作用, 探索对其野生近缘种生境的 有效保护策略, 同时着力提高水生作物及其野生近 缘种的基础研究水平，培育更多的优质栽培品种。

\section{4 经济作物一一油桐}

油桐(Vernicia fordii)是我国特有的经济林木, 原产于长江流域中下游丘陵常绿阔叶林。油桐与油 茶(Camellia oleifera)、核桃(Juglans regia)、乌柏 (Sapium sebiferum)并列为我国四大木本油料作物, 具有上千年的栽培历史。油桐属于边际性经济林树 种, 不占用耕地, 在长江流域分布广泛, 同时具有 重要的工业价值、能源价值以及一定的药用价值和
生态价值, 存在非常大的开发潜力(傅登祺和黄宏 文, 2006)。

从油桐果提取的桐油数世纪以来一直是涂料 和油漆的生产原料。桐油曾是我国生产的重要战略 资源之一, 长期出口国外且供不应求。然而, 由于 石油化工业的发展和桐油替代品的不断出现, 加之 对桐油的应用基础和深度开发技术研究力度严重 不足，使得其市场竞争力一落千丈。在这种情况下， 农民种植油桐的积极性下降，许多地方油桐林被砍 伐，国家和地方政府也一度中止了对油桐科研项目 的资助, 对我国油桐资源造成了极大冲击, 多数地 方品种濒临灭绝(谭晓风, 2006)。进入21世纪，在化 石能源供给紧张、环境问题日益严重的形势下，油 桐作为环保且可再生的植物能源再度引起广泛关 注。桐油不仅可用作生产生物柴油的极佳原料或重 要添加成分, 而且基于桐油生产的油漆能有效避免 人工合成油漆带来的环境污染; 此外，油桐的适生 区域多为山区，发展油桐种植能提高当地人民的收 入(张玲玲和彭俊华, 2011)。目前, 我国很多地区开 始恢复油桐生产，扩大油桐种植面积。我国科研工 作者也已在油桐种质资源的收集、品种分类、优良 家系与无性系的选育、引种栽培措施等方面开展了 一系列研究。然而油桐及其近缘种的遗传多样性还 有待进一步挖掘和评估，桐油生物合成的调控机制 仍需深入研究。从生产上看, 油桐育种周期长, 费时 耗力, 因此育种技术有待提高, 并要加大科技成果 的推广力度, 改变目前油桐林多为半野生和粗放式 管理的状态(方嘉兴和何方, 1998; 谭晓风, 2006)。

油桐的兴衰历程折射出经济植物的重要性会 因市场的需求变化而发生波动, 进而影响其遗传资 源的保护，芳麻(Boehmeria nivea)、漆树(Toxicodendron vernicifluum)与橡胶树(Hevea brasiliensis) 等也是如此。我们需要运用动态的、长远的眼光来 看待植物资源, 针对重要植物资源制定有预见性 的、长期的保护规划，而不能被短期利益所驱动。 植物遗传资源一旦丧失则很难恢复，尤其是那些稀 有的基因资源。随着科技水平的提高和人类需求的 不断发展，传统作物的用途和野生植物资源的潜在 价值将被不断挖掘和利用。

\section{结语}

步入 21 世纪，持续增长的人口和变化的生态环 
境不仅使人类社会发展面临一系列挑战, 而且对现 代农业生产提出了新的要求。一方面, 人口的急剧 增长以及与其相伴随的城市扩张和耕地流失, 导致 提高农作物单位面积产量成为一种刚性需求 (Cohen, 2003); 人类对植物资源的多元化需求也对 农作物种类和品质的多样化提出了更高要求。另一 方面, 全球气候变化、极端气候事件增多和土地利 用率增加等因素又对栽培植物野生近缘种的存续 和发展造成了较大威胁(Ramesh et al, 2017)。栽咅 植 物野生近缘种是保障粮食安全和农业可持续发展 的基础, 需要制定合理的策略加以积极、有效地保 护(马克平, 2012), 尤其要重视对野生近缘种遗传多 样性和进化潜力的保护, 以实现对栽培作物野生近 缘种资源的可持续利用。与此同时, 对栽培植物野 生近缘种资源的利用不能仅停留在对已有品种的 改良上, 需要突破野生近缘种创新利用的瓶颈, 挖 掘和引种驯化更多的野生植物, 拓展利用途径, 为 人类生存和发展提供更多的植物资源。

\section{参考文献}

Barnosky AD, Hadly EA, Gonzalez P, Head J, Polly PD, Lawing AM, Eronen JT, Ackerly DD, Alex K, Biber E, Blois J, Brashares J, Ceballos G, Davis E, Dietl GP, Dirzo R, Doremus R, Fortelius M, Greene HW, Hellmann J, Hickler T, Jackson ST, Kemp M, Koch PL, Kremen C, Lindsey EL, Looy C, Marshall CR, Mendenhall C, Mulch A, Mychajliw AM, Nowak C, Ramakrishnan U, Schnitzler J, Shrestha KD, Solari K, Stegner L, Stegner MA, Stenseth NC, Wake MH, Zhang Z (2017) Merging paleobiology with conservation biology to guide the future of terrestrial ecosystems. Science, 355, 594.

Barton L, Newsome SD, Che FH, Wang H, Guilderson TP, Bettinger RL (2009) Agricultural origins and the isotopic identity of domestication in northern China. Proceedings of National Academy of Sciences, USA, 106, 5523-5528.

Brozynska M, Furtado A, Henry RJ (2015) Genomics of crop wild relatives: Expanding the gene pool for crop improvement. Plant Biotechnology Journal, 14, 1070-1085.

Carroll SP, Jørgensen PS, Kinnison MT, Bergstrom CT, Denison RF, Gluckman P, Smith TB, Strauss SY, Tabashnik BE (2014) Applying evolutionary biology to address global challenges. Science, 346, 1245993.

Castañeda-Álvarez NP, Khoury CK, Achicanoy HA, Bernau V, Dempewolf H, Eastwood RJ, Guarino L, Harker RH, Jarvis A, Maxted N, Müller JV, Ramirez-Villegas J, Sosa CC, Struik PC, Vincent H, Toll J (2016) Global conservation priorities for crop wild relatives. Nature Plants, 2, 16022.

Chao S (2007) Evaluation of genetic diversity and ge- nome-wide linkage disequilibrium among US wheat (Triticum aestivum L.) germplasm representing different market classes. Crop Science, 47, 1018-1030.

Chen YP, Chen YF, Zhao JT, Huang X, Huang XL (2007) Cloning and expression of resistance gene analogs (RGAs) from wild banana resistant to banana fusarium wilt. Journal of Plant Physiology and Molecular Biology, 33, 567-573. (in Chinese with English abstract) [陈雅平, 陈云凤, 赵杰 堂, 黄霞, 黄学林 (2007) 抗香蕉枯萎病的野生蕉抗病基 因类似序列的克隆与表达. 植物生理与分子生物学学报, 33, 567-573.]

Cohen JE (2003) Human population: The next half century. Science Magazine, 302, 1172-1175.

Collard BCY, Jahufer MZZ, Brouwer JB, Pang ECK (2005) An introduction to marker, quantitative trait loci (QTL) mapping and marker-assisted selection for crop improvement: The basic concepts. Euphytica, 142, 169-196.

Compilation Group of China's Biodiversity: A Country Study (2016) China’s Biodiversity: A Country Study. China Environmental Science Press, Beijing. (in Chinese) [中国生物多 样性国情研究报告编写组 (2016) 中国生物多样性国情 研究报告. 中国环境科学出版社, 北京.]

Dehaan LR, van Tassel DL, Anderson JA, Asselin SR, Barnes R, Baute GJ, Cattani DJ, Culman SW, Dorn KM, Hulke BS, Kantar M, Larson S, Marks MD, Miller AJ, Poland J, Ravetta DA, Rude E, Ryan MR, Wyse D, Zhang XF (2016) A pipeline strategy for grain crop domestication. Crop Science, 56, 1-14.

Denison RF, Kiers ET, West SA (2003) Darwinian agriculture: When can humans find solutions beyond the reach of natural selection? Quarterly Review of Biology, 78, 145-168.

Diamond J (2002) Evolution, consequences and future of plant and animal domestication. Nature, 418, 700-707.

Doebley JF, Gaut BS, Smith BD (2006) The molecular genetics of crop domestication. Cell, 127, 1309-1329.

Donald CM (1981) Competitive plants, communal plants, and yields in wheat crops. In: Wheat Science-Today and Tomorrow (eds Evans LT, Peacock WJ). Cambridge University Press, Cambridge, UK.

Dong YC (1999) The current situation and prospect of crop germplasm resource researches in China. Review of China Agricultural Science \& Technology, (2), 36-40. (in Chinese) [董玉琛 (1999) 我国作物种质资源研究的现状与展望. 中国农业科技导报, (2), 36-40.]

Dong YC, Liu X (2008) Crops and Their Wild Relatives in China. China Agriculture Press, Beijing. (in Chinese) [董玉 琛, 刘旭 (2008) 中国作物及其野生近缘植物. 中国农业 出版社, 北京.]

Dulloo ME, Hunter D, Borelli T, Hamon S, Pamfil D, Sestras R (2010) Ex situ and in situ conservation of agricultural biodiversity: Major advances and research needs. Notulae Botanicae Horti Agrobotanici Cluj-Napoca, 38, 114-122.

Fang JX, He F (1998) Chinese Tung Oil Tree. Chinese Forestry 
Publishing House, Beijing. (in Chinese) [方嘉兴, 何方 (1998) 中国油桐. 中国林业出版社, 北京.]

FAO (2014) Genebank Standards for Plant Genetic Resources for Food and Agriculture. Food and Agriculture Organization of the United Nations, Rome, Italy.

Fowler C (2008) The svalbard seed vault and crop security. Bioscience, 58, 190-191.

Frankham R, Briscoe DA, Ballou JD (2002) Introduction to Conservation Genetics. Cambridge University Press, Cambridge.

Fu DQ, Huang HW (2006) Brief introduction of exploitation and utilization of fuel plants resources. Journal of Wuhan Botanical Research, 24, 183-190. (in Chinese with English abstract) [傅登祺, 黄宏文 (2006) 能源植物资源及其开 发利用简况. 武汉植物学研究, 24, 183-190.]

Fu LK (1991) China Plant Red Data Book, Vol.1: Rare and Endangered Plants. Science Press, Beijing. (in Chinese) [傅 立国 (1991) 中国植物红皮书: 稀有濒危植物(第一册). 科学出版社, 北京.]

Fuller DQ (2007) Contrasting patterns in crop domestication and domestication rates: Recent archaeobotanical insights from the Old World. Annals of Botany, 100, 903-924.

Gómez-Campo C (1985) Seed banks as an emergency conservation strategy. In: Plant Conservation in the Mediterranean Area (ed. Gomez-Campo C), pp. 237-247. Dr. W. Junk, Dordrecht.

Gross BL, Olsen KM (2010) Genetic perspectives on crop domestication. Trends in Plant Science, 15, 529-537.

Guo HB, Ke WD, Li SM, Peng J (2004) Cluster analysis of Nelumbo accessions based on RAPD markers. Journal of Plant Genetic Resources, 5, 328-332. (in Chinese with English abstract) [郭宏波, 柯卫东, 李双梅, 彭静 (2005) 不 同类型莲资源的RAPD聚类分析. 植物遗传资源学报, 5, 328-332.]

Hajjar R, Hodgkin T (2007) The use of wild relatives in crop improvement: A survey of developments over the last 20 years. Euphytica, 156, 1-13.

Hamblin MT, Salas Fernandez MG, Casa AM, Mitchell ME, Paterson AH, Kresovich S (2005) Equilibrium processes cannot explain high levels of short- and medium-range linkage disequilibrium in the domesticated grass Sorghum bicolor. Genetics, 171, 1247-1256.

Hanson JO, Rhodes JR, Rigino C, Fuller RA (2017) Environmental and geographic variables are effective surrogates for genetic variation in conservation planning. Proceedings of National Academy of Sciences, USA, 114, 12755-12760.

Heffner EL, Sorrells ME, Jannink J (2009) Genomic selection for crop improvement. Crop Science, 49, 1-12.

Hendry AP (2013) Key questions in the genetics and genomics of eco-evolutionary dynamics. Heredity, 111, 456-466.

Huang HW (2009) History of 100 years of domestication and improvement of kiwifruit and gene discovery from genetic introgressed populations in the wild. Chinese Bulletin of
Botany, 44, 127-142. (in Chinese with English abstract) [黄 宏文 (2009) 狝猴桃驯化改良百年启示及天然居群遗传 渐渗的基因发掘. 植物学报, 44, 127-142.]

Ingvarsson PK (2002) A metapopulation perspective on genetic diversity and differentiation in partially self-fertilizing plants. Evolution, 56, 2368-2373.

Jacob P, Avni A, Bendahmane A (2017) Translational research: Exploring and creating genetic diversity. Trends in Plant Science, 23, 42-52.

Jarvis DI, Myer L, Klemick H, Guarino L, Smale M, Brown AHD, Sadiki M, Sthapit B, Hodgkin T (2000) A Training Guide for In Situ Conservation On-Farm. Version 1. International Plant Genetic Resource Institute, Rome, Italy.

Jena KK (2010) The species of the genus Oryza and transfer of useful genes from wild species into cultivated rice, $O$. sativa. Breeding Science, 60, 518-523.

Jia JZ, Gao LF, Zhao GY, Zhou WB, Zhang WJ (2015) Crop genomics and crop science revolutions. Scientia Agricultura Sinica, 48, 3316-3332. (in Chinese with English abstract) [贾继增, 高丽锋, 赵光耀, 周文斌, 张卫健 (2015) 作物 基因组学与作物科学革命. 中国农业科学, 48, 3316-3332.]

Karkute SG, Singh AK, Gupta OP, Singh PM, Singh B (2017) CRISPR/Cas9 mediated genome engineering for improvement of horicultural crops. Frontiers in Plant Science, 8, 1635.

Kovach MJ, Sweeney MT, McCouch SR (2007) New insights into the history of rice domestication. Trends in Genetics, 23, 578-587.

Li DZ, Yang XY, Wang YH, Cai J (2010) The germplasm bank of wild species, Southwest China. Bulletin of Chinese Academy of Sciences, 25, 565-569. (in Chinese) [李德铢, 杨湘云, 王雨华, 蔡杰 (2010) 中国西南野生生物种质资 源库. 中国科学院院刊, 25, 565-569.]

Li L, Chen JK (2014) Influence of climate change on wild plants and the conservation strategies. Biodiversity Science, 22, 549-563. (in Chinese with English abstract) [黎否, 陈 家宽 (2014) 气候变化对野生植物的影响及保护对策. 生物多样性, 22, 549-563.]

Li Y, Li YH, Yang QW, Zhang JP, Zhang JM, Qiu LJ, Wang TY (2015) Genomics-based crop germplasm research: Advances and perspectives. Scientia Agricultura Sinica, 48, 3333-3353. (in Chinese with English abstract) [黎裕, 李英 慧, 杨庆文, 张锦鹏, 张金梅, 邱丽娟, 王天宇 (2015) 基于基因组学的作物种质资源研究: 现状与展望. 中国 农业科学, 48, 3333-3353.]

Liu ZS (2014) Progress in crop genetic breeding. V. Phenotypic selection and genotypic selection. Crop Research, 28, 780-784. (in Chinese with English abstract) [刘忠松 (2014) 作物遗传育种研究进展. V. 表型选择与基因型选择. 作 物研究, 28, 780-784.]

Lu BR (2014) Genetic and evolutionary effects of hybridization-introgression and their implications for conservation of 
crop wild relative species. Chinese Science Bulletin, 59, 479-492. (in Chinese with English abstract) [卢宝荣 (2014) 杂交-渐渗的遗传进化效应与栽培作物野生近缘种多样 性保护. 科学通报, 59, 479-492.]

Ma KP (2012) Studies and conservation of crop wild relatives should be promoted. Biodiversity Science, 20, 641-642. (in Chinese) [马克平 (2012) 作物野生近缘种的研究与保护 需要重视. 生物多样性, 20, 641-642.]

Maxted N, Ford-Lloyd BV, Jury S, Kell S, Scholten M (2006) Towards a definition of a crop wild relative. Biodiversity and Conservation, 15, 2673-2685.

Maxted N, Kell S, Toledo Á, Dulloo E, Heywood V, Hodgkin T, Hunter D, Guarino L, Jarvis A, Ford-Lloyd B (2010) A global approach to crop wild relative conservation: Securing the gene pool for food and agriculture. Kew Bulletin, 65, 561-576.

Meilleur BA, Hodgkin T (2004) In situ conservation of crop wild relatives: Status and trends. Biodiversity and Conservation, 13, 663-684.

Meyer RS, Duval AE, Jensen HR (2012) Patterns and processes in crop domestication: An historical review and quantitative analysis of 203 global food crops. New Phytologist, 196, 29-48.

Michael TP, Vanburen R (2015) Progress, challenges and the future of crop genomes. Current Opinion in Plant Biology, 24, 71-81.

Moose SP, Mumm RH (2008) Molecular plant breeding as the foundation for 21st century crop improvement. Plant Physiology, 147, 969-977.

Munns R, James RA, Xu B, Athman A, Conn SJ, Jordans C, Byrt CS, Hare RA, Tyerman SD, Tester M, Plett D, Gilliham $M$ (2012) Wheat grain yield on saline soils is improved by an ancestral $\mathrm{Na}^{+}$transporter gene. Nature Biotechnology, 30, 360-364.

Nielson R (2005) Molecular signatures of natural selection. Annual Reviews of Genetics, 39, 197-218.

Ning X, Zhang WL, Huang JN, Yan YF, Yan CQ, Yang L (2014) Identification of new rice germplasms for resistance to bacterial blight from Oryza meyeriana Baili. Journal of Plant Genetic Resources, 15, 620-624. (in Chinese with English abstract) [宁茜, 张维林, 黄佳男, 阎轶峰, 严成 其, 杨玲 (2014) 来源于疮粒野生稻的白叶枯病新抗源 的鉴定. 植物遗传资源学报, 15, 620-624.]

Palaisa K, Morgante M, Tingey S, Rafalski A (2004) Long-range patterns of diversity and linkage disequilibrium surrounding the maize Y1 gene are indicative of an asymmetric selective sweep. Proceedings of the National Academy of Sciences, USA, 101, 9885-9890.

Pimentel D, Wilson C, McCullum C, Huang R, Dwen P, Flack J, Tran Q, Saltman T, Cliff B (1997) Economic and environmental benefits of biodiversity. BioScience, 47, 747-757.

Prentis PJ, Wilson JR, Dormontt EE, Richardson DM, Lowe AJ (2008) Adaptive evolution in invasive species. Trends in
Plant Science, 13, 288-294.

Purugganan MD, Fuller DQ (2009) The nature of selection during plant domestication. Nature, 457, 843-848.

Qian J, He T, Song ZP, Lu BR (2005) Genetic evaluation of in situ conserved and reintroduced populations of wild rice (Oryza rufipogon: Poaceae) in China. Biochemical Genetics, 43, 561-575.

Qin DD, Dong J, Xu FC, Xu Q, Ge ST, Du J, Li MF (2016) Innovation and utilization of crop germplasm resources during the era of molecular breeding. Barley and Cereal Sciences, 33, 1-4. (in Chinese with English abstract) [秦丹丹, 董静, 许甫超, 徐晴, 葛双桃, 杜静, 李梅芳 (2016) 分 子育种时代的作物种质资源创新与利用. 大麦与谷类科 学, 33, 1-4.]

Ramesh K, Matloob A, Aslam F, Florentine SK, Chauhan BS (2017) Weeds in a changing climate: Vulnerabilities, consequences, and implications for future weed management. Frontiers in Plant Science, 8, 95.

Rodriguez-Leal D, Lemmon ZH, Man J, Bartlett, Lippman ZB (2017) Engineering quantitative trait variation for crop improvement by genome editing. Cell, 171, 470-480.

Ronald PC (2014) Lab to farm: Applying research on plant genetics and genomics to crop improvement. PLoS Biology, 12, e1001878.

Song ZP, Li B, Chen JK, Lu BR (2005) Genetic diversity and conservation of common wid rice (Oryza rufipogon) in China. Plant Species Biology, 20, 83-92.

Soulé MD (1985) What is conservation biology? Bioscience, 35, 727-734.

Subbaiyan GK, Waters DLE, Katiyar SK, Sadananda AR, Vaddadi S, Henry RJ (2012) Genome-wide DNA polymorphisms in elite indica rice inbreds discovered by whole-genome sequencing. Plant Biotechnology Journal, 10, 623-634.

Tan XF (2006) Status and suggestion on development of Vernicia fordii. Nonwood Forest Research, 24(3), 62-64. [谭晓 风 (2006) 油桐的生产现状及其发展建议. 经济林研究, 24(3), 62-64.]

van Slageren W (2003) The millennium seed bank: Building partnerships in arid regions for the conservation of wild species. Journal of Arid Environments, 54, 195-201.

Vaughan DA (1994) The Wild Relatives of Rice: A Genetic Resources Handbook. International Rice Research Institute, Manila.

Vavilov NI (translated by Dong YC) (1982) Origin and Geography of Cultivated Plants. China Agriculture Press, Beijing. (in Chinese) [瓦维洛夫(著) 董玉琛(译) (1982) 主要栽培 植物的世界起源中心. 中国农业出版社, 北京.]

Wang BN, Huang Z, Shu LH, Ren X, Li XH, He GC (2001) Mapping of two new brown planthopper resistance genes from wild rice. Chinese Science Bulletin, 46, 1092-1095. (in Chinese with English abstract) [王布哪, 黄臻, 舒理慧, 任 翔, 李香花, 何光存 (2001) 两个来源于野生稻的抗褐飞 
風新基因的分子标记定位. 科学通报, 46, 1092-1095.]

Wang S, Xie Y (2004) China Species Red List, Vol.1: Red List. Higher Education Press, Beijing. (in Chinese) [汪松, 谢炎 (2004) 中国物种红色名录, 第一卷: 红色名录. 高等教 育出版社, 北京.]

Warschefsky E, Penmetsa RV, Cook DR, von Wettberg EJB (2014) Back to the wilds: Tapping evolutionary adaptations for resilient crops through systematic hybridization with crop wild relatives. American Journal of Botany, 101, 1791-1800.

Weiner J (2003) Ecology-The science of agriculture in the 21st century. Journal of Agricultural Science, 141, 371-377.

Weiner J, Du YL, Zhang C, Qin XL, Li FM (2017) Evolutionary agroecology: Individual fitness and population yield in wheat (Triticum aestivum). Ecology, 98, 2261-2266.

Willcox G (2005) The distribution, natural habitats and availability of wild cereals in relation to their domestication in the Near East: Multiple events, multiple centres. Vegetation History and Archaeobotany, 14, 534-541.

Xu K, Xu X, Fukao T, Canlas P, Maghirang-Rodriguez R, Heuer S, Ismail AM, Bailey-Serres J, Ronald PC, Mackill DJ (2006) Sub1A is an ethylene response-factor-like gene that confers submergence tolerance to rice. Nature, 442, 705-708.

Yang M, Liu F, Han YN, Xu LM, Juntawong N, Liu YN (2013) Genetic diversity and structure in populations of $\mathrm{Ne}$ lumbo from America, Thailand and China: Implications for conservation and breeding. Aquatic Botany, 107, 1-7.

Yang QW, Qin WB, Zhang WX, Qiao WH, Yu SN, Guo Q (2013) In-situ conservation practices and future development of wild relatives of crops in China. Journal of Plant Genetic Resources, 14, 1-7. (in Chinese with English abstract) [杨庆文, 秦文斌, 张万霞, 乔卫华, 于寿娜, 郭青 (2013) 中国农业野生植物原生境保护实践与未来研究方 向. 植物遗传资源学报, 14, 1-7.]

You XL (2009) Neolithic culture in the Yangtze River Basin. In: Chinese Agricultural History-Primitive Society (eds Du
YL, Sun ZC), pp. 113-122. China Agriculture Press, Beijing. (in Chinese) [游修龄 (2009) 长江流域新石器时代文 化. 见: 中国农业通史一一原始社会卷(杜言林, 孙政才 主编), 113-122页. 中国农业出版社, 北京.]

Yu YB, Wang QL, Kell S, Maxted N, Ford-Lloyd BV, Wei W, Kang DM, Ma KP (2013) Crop wild relatives and their conservation strategies in China. Biodiversity Science, 21, 750-757. (in Chinese with English abstract) [于燕波, 王群 亮, Kell S, Maxted N, Ford-Lloyd BV, 魏伟, 康定明, 马 克平 (2013) 中国栽培植物野生近缘种及其保护对策. 生物多样性, 21, 750-757.]

Zhang H, Mittal N, Leamy LJ, Barazani O, Song BH (2017) Back into the wild-Apply untapped genetic diversity of wild relatives for crop improvement. Evolutionary Applications, 10, 5-24.

Zhang DY, Sun GJ, Jiang XH (1999) Donald's ideotype and growth redundancy: A game theoretical analysis. Field Crops Research, 61, 179-187.

Zhang LL, Peng JH (2011) Values, development and utilization prospect of Vernicia fordii resources. Nonwood Forest Resaerch, 29, 130-136. (in Chinese with English abstract) [张 玲玲，彭俊华 (2011) 油桐资源价值及其开发利用前景. 经济林研究, 29, 130-136.]

Zhao Y (2014) The Mechanism Shaping Distribution Pattern of Population Variations in Oryza rufipogon Griff. PhD dissertation, Fudan University, Shanghai. (in Chinese with English abstract) [赵耀 (2014) 普通野生稻种群变异的分布格局 及其形成机制. 博士学位论文, 复旦大学, 上海.]

Zhou XC, Xing YZ (2016) The application of genome editing in identification of plant gene function and crop breeding. Hereditas (Beijing), 38, 227-242. (in Chinese with English abstract) [周想春, 邢永忠 (2016) 基因组编辑技术在植 物基因功能鉴定及作物育种中的应用。遗传，38, 227-242.]

(责任编辑：黄祥忠)

\section{附录 Supplementary Material}

附录1 中国重要作物种质资源的迁地保护状况统计

Appendix 1 Statistics on ex situ conservations of important crop germplasm resources in China http://www.biodiversity-science.net/fileup/PDF/2018029-1.pdf 
赵耀，李耕耘，杨继. 栽培植物野生近缘种的保护与利用. 生物多样性, 2018, 26 (4): 414-426.

http://www.biodiversity-science.net/CN/10.17520/biods.2018029

附录1 中国重要作物种质资源的迁地保护状况统计(数据来源: 中国作物种质资源信息系统 www.cgris.net)

Appendix 1 Statistics on ex situ conservations of important crop germplasm resources in China (Data source: Chinese Crop Germplasm Information System, www.cgris.net)

\begin{tabular}{llll}
\hline 名称 Name & 地点 Location & 作物 Crop & $\begin{array}{l}\text { 保存份数 物种数 } \\
\text { No. of accessionsNo. of species }\end{array}$ \\
\end{tabular}

\section{种质围 Germplasm nursery}

\section{粮食作物 Food crop}

国家种质广州野生稻围

National Wild Rice Germplasm Nursery, Guangzhou

国家种质南宁野生稻围

National Wild Rice Germplasm Nursery, Nanning

中国农科院多年生小麦野生近缘植物圃

Perennial Wild Relatives of Wheat Germplasm Nursery of 北京 Beijing

Chinese Academy of Agricultural Sciences (CAAS)

\section{经济作物 Economic crop}

国家种质杭州茶树圃

National Tea Germplasm Nursery, Hanzhou

国家种质镇江桑树圃

National Mulberry Germplasm Nursery, Zhenjiang

国家种质沅江拦麻戋

National Ramie Germplasm Nursery, Yuanjiang

国家种质开远甘蔗围

National Sugarcane Germplasm Nursery, Kaiyuan

中国热带农科院橡胶热作种质圃

Rubber and Tropical Crop Germplasm Nursery of Chinese Danzhou, Hainan

Tropical Academy of Agricultural Sciences

中国农科院海南野生棉种质围

Wild Cotton Germplasm Nursery of CAAS, Hainan

\section{果树作物 Fruit crop}

国家果树种质兴城梨、苹果戋

National Fruit Tree Germplasm Nursery of Pear and Apple, Xingcheng,

Xingcheng

国家果树种质郑州葡萄、桃围

National Fruit Tree Germplasm Nursery of Grape and

Peach, Zhengzhou

\section{国家果树种质重庆柑桔戋}

National Fruit Tree Germplasm Nursery of Orange,

Chongqing

国家果树种质泰安核桃、板栗戋
National Fruit Tree Germplasm Nursery of Walnut and
Chinese Chestnut, Tai’an

国家果树种质南京桃、草莓戋

National Fruit Tree Germplasm Nursery of Peach and

Strawberry, Nanjing

国家果树种质眉县柿圃

National Fruit Tree Germplasm Nursery of Persimmon, Meixian

国家果树种质太谷麥、葡萄圃
National Fruit Tree Germplasm Nursery of Jujube and
Grape, Taigu

国家果树种质武昌砂梨圃

National Fruit Tree Germplasm Nursery of Pear, Wuchang Wuhan, Hubei

国家果树种质公主岭寒地果树戋

National Cold Region Fruit Tree Germplasm Nursery,Gongzhuling, Jilin Gongzhuling
海南三亚

Sanya, Hainan

辽宁兴城

Liaoning

\section{浙江杭州 \\ Zhenjiang, Jiangsu \\ 湖南沅江 \\ 云南开远 \\ Kaiyuan, Yunnan}

河南郑州

Zhengzhou, Henan

重庆 Chongqing

山东泰安

Tai'an, Shandong

江苏南京

Nanjing, Jiangsu

陕西眉县

Meixian, Shaanxi

\section{山西太谷}

Taigu, Shanxi

湖北武汉

吉林公主岭 
赵耀, 李耕耘, 杨继. 栽培植物野生近缘种的保护与利用. 生物多样性, 2018, 26 (4): 414-426.

http://www.biodiversity-science.net/CN/10.17520/biods.2018029

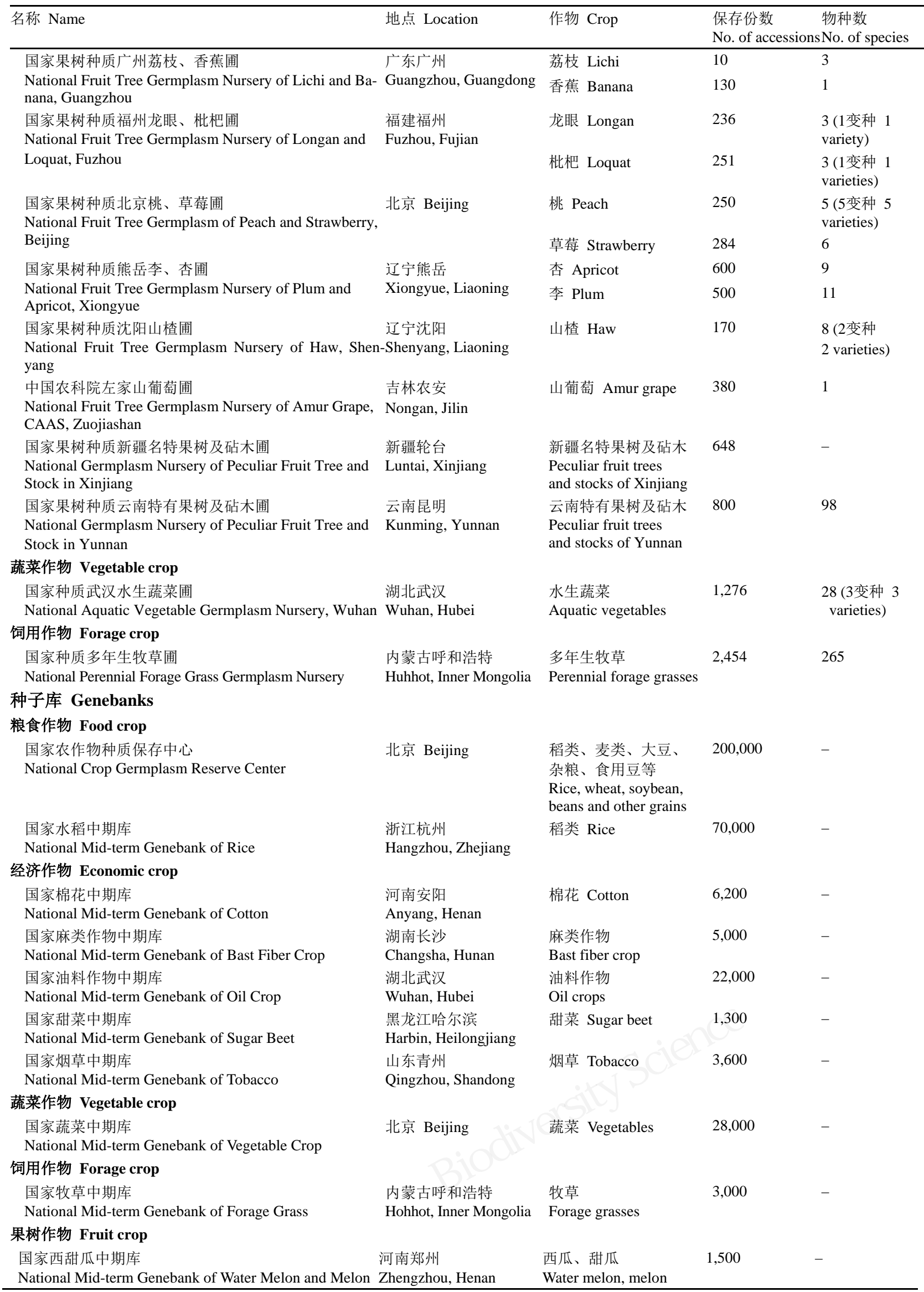

